\title{
Environmental and economic consequences of soil water repellency under pasture
}

\author{
K. MÜLLER ${ }^{1}$, M. DEURER ${ }^{2}$, M. SLAY ${ }^{3}$, T. ASLAM ${ }^{2}$, J.A. CARTER ${ }^{2}$ and B.E. CLOTHIER ${ }^{2}$ \\ ${ }^{1}$ The New Zealand Institute for Plant \& Food Research Ltd, East Street, Hamilton \\ ${ }^{2}$ The New Zealand Institute for Plant \& Food Research Ltd, Tennent Drive, Palmerston North \\ ${ }^{3}$ AgTechnology and Advisory Service, Homelea, Shanley Road, RD 9, Hastings \\ karin.mueller@plantandfood.co.nz
}

\begin{abstract}
Our current survey revealed that soil water repellency (SWR) is a widespread phenomenon under pasture in the North Island. If present, SWR controls soil water dynamics. Runoff and preferential flow of water and contaminants and reductions in pasture growth are possible consequences. We quantified the impact of SWR on soil water dynamics at two hill country pasture sites. Our objectives were to assess how SWR impacts on the soil's buffering for water, and to assess if SWR leads to reduced pasture growth. Initial results show that SWR reduced infiltration rates by up to a factor of 20 and increased runoff rates. Pasture growth was reduced between 5 and $20 \%$. SWR increased the risk of contaminant loss and compromised pasture production. We need research to better understand the source of SWR so that efficient and affordable mitigation strategies can be developed.
\end{abstract}

Keywords: soil hydrophobicity, intrinsic sorptivity, infiltration

\section{Introduction}

There is increasing concern about soil water repellency (SWR) as a soil degradation process. In the 1990s, New Zealand soil research addressed some issues of SWR (Horne \& McIntosh 2000; Wallis et al. 1991). The higher frequency of droughts in recent years is the main trigger of SWR and its increased spread. It is an important issue for primary industries and amenity turf.

SWR is the phenomenon when a soil does not wet up spontaneously. It is a transient property and will occur whenever soils dry out below a "critical soil water content' (Dekker \& Ritsema 1994). SWR poses a threat to the soil's ecosystem services including its ability to store water for plant growth. In a hydrophilic dry soil, water infiltrates across the entire cross-section of the soil surface while in soils suffering from SWR, water infiltrates only across a fraction of the soil surface in the form of fingers or it runs off. Consequently, water in water-repellent soil layers is unevenly distributed, and such layers store less water than if they were hydrophilic. Reductions in pasture growth are another possible consequence of SWR. Roy \& McGill (2002) stated that the probability of annual crops performing normally is low in extremely hydrophobic soils. A true understanding of the ecological and economic significance of SWR is still limited.

The objectives of our study were:

To evaluate the ratio of the intrinsic permeabilities and sorptivities of ethanol to water as an effective measure of a soil's reduced buffering capacity for water

To assess if a reduced buffering of water through SWR could be responsible for a reduced filtering capacity of soils and reduced pasture growth

To assess the occurrence of SWR in some pastoral systems in the North Island.

\section{Methods}

\section{Measurement of SWR}

Two sites under permanent pasture in silt loam soils classified as Cambisols (FAO classification, Driessen et al. 2001) and characterised by large differences in soil organic carbon (SOC) content were selected on AgResearch's Hill Country Farm, Whatawhata, Waikato. The topsoil $(0-0.1 \mathrm{~m})$ of the high-SOC site (with $\left.8.7 \mathrm{~kg} \mathrm{SOC} / \mathrm{m}^{2}\right)$ has about $30 \%(\mathrm{P}<0.05)$ more SOC than the low-SOC site (with $6.3 \mathrm{~kg} \mathrm{SOC/}$ $\mathrm{m}^{2}$ ). In February 2007, we collected undisturbed soil columns $(0.3 \times 0.2 \times 0.1 \mathrm{~m})$ in 6 replicates. We used a wet-sieving technique (Elliott 1986) to separate the macro-aggregates into four selected fractions, $>4.75$, 4.75-2.80, 2.8-1.00, and 1.0-0.25 mm. We analysed the occurrence of SWR at the aggregate scale because the functional component of filtering in the soil is the aggregate. The degree of SWR was measured with the Molarity of Ethanol Droplet (MED) test (Roy \& McGill 2002). The results were converted to contact angles (CA). Soils with CAs larger than $90^{\circ}$ are strongly water repellent or hydrophobic.

\section{Measurement of environmental and economic consequences of SWR}

We quantified how SWR modified some selected soil services at our experimental sites. We chose water infiltration and solute transport as important soil services for pasture production, water regulation and 
protection of water quality.

The impact of SWR on infiltration was assessed by comparing the infiltration of water with that of ethanol using glass disc infiltrometers in the field. In the laboratory, we also measured the absorption of water and ethanol into the four macro-aggregate fractions of our two soils with a modified Hayne's apparatus at two tensions (-10 and $-20 \mathrm{~mm}$ ). The sorptivity of each aggregate size fraction $(0.25-1 ; 1-2.8,2.8-4.75 ;>4.75$ $\mathrm{mm}$ ) was measured with water and ethanol in triplicate at both tensions. We calculated the ratios of the intrinsic permeability and sorptivity of ethanol to the intrinsic permeability and sorptivity of water to quantify by how much the water infiltration and absorption was limited by SWR. The intrinsic permeability/sorptivity takes account of the fluid used in the experiment and it should be the same in a hydrophilic soil, whether determined by ethanol or water. Thus, in a hydrophilic soil the ratio is one.

In the laboratory, we measured the transport of the herbicide 2,4-D in intact soil columns $(10 \mathrm{~cm}$ diameter $\mathrm{x} 11 \mathrm{~cm}$ length) collected at our two pastoral sites at the end of summer. We applied a pulse of 2,4-D (typical field application rate of $2 \mathrm{l} / \mathrm{ha}$ ) to the dry soil and leached it under unsaturated conditions through the soils. The experiments were conducted in triplicate. The calculated filtering efficiency of the soils describes the fraction of the herbicide retained in the soil as a function of the leachate volumes (drainage). For example, if $100 \%$ of $2,4-\mathrm{D}$ is retained in the soil, then the filtering efficiency is one.

At Maraetotara (Hawke's Bay), the incidence of 'Dry Patch Syndrome' has been related to the occurrence of SWR (Deurer et al. 2007). We chose three hydrophobic and three control sites. In December 2009, we installed three pasture cages $(1 \times 0.45 \mathrm{~m})$ at each site and started measuring the dry matter production in duplicate frames of $0.3 \times 0.3 \mathrm{~m}$ within each cage, and the persistence of the soils' water repellency using the Water Drop Penetration Time (WDPT) test on oven-dried $\left(105^{\circ} \mathrm{C}\right.$ for $24 \mathrm{~h}$ ) topsoil samples (Bisdom et al. 1993), monthly. The measurements are ongoing.

\section{Survey on SWR}

We designed a survey to assess the occurrence of SWR under pasture in the North Island. We selected 50 sites by using three criteria; soil order, annual water deficit (AWD) and profile available water (PRAW). We classified AWD and PRAW into three categories each. The survey covered the ten dominant soil orders of the North Island. Within each of the soil orders, the sampling was stratified according to climate (AWD) and physical soil properties (PRAW). We chose five combinations of AWD and PRAW within each soil order. The largest areas in the North Island with a given combination of soil order, and AWD and PRAW were determined using ArcGIS. Between November 2009 and January 2010, we collected five bulk topsoil samples in a star-shaped pattern, each sample approximately $25 \mathrm{~m}$ apart, and measured SWR with the MED and WDPT tests, $\mathrm{pH}$, SOC and bulk density. This analysis is in progress.

\section{Statistical analysis}

The results were analysed with a one- or two-factorial ANOVA with Genstat 9.1.0.150 software. In the twofactorial ANOVA, the first factor was the soil carbon status and the macro-aggregate size was the second factor. We interpreted the differences between means of properties to be significant if they were larger than their respective least significant differences (LSD) at the $95 \%$ confidence level.

\section{Results and Discussion}

The two Whatawhata soils were highly structured. Four macro-aggregate fractions contributed about $91 \%$ of the total soil weight at both sites. The fractions of macro-aggregates were significantly $(\mathrm{P}<0.01)$ different in all aggregate sizes, apart from $0.25-1.0 \mathrm{~mm}$ (Fig. 1A). At the time of sampling (February 2007), all soil aggregates were water repellent, with $\mathrm{CA} \geq 90^{\circ}$. The contact angles of the individual aggregate sizes were significantly different $(\mathrm{P}<0.05)$, with the exception of the aggregate size $2.8-4.75 \mathrm{~mm}$. The macro-aggregates of the high-SOC site had significantly higher CA than those of the low-SOC site (Fig. 1B). Potential drivers are clay mineralogy, $\mathrm{pH}$ and $\mathrm{SOC}$ contents. It seems highly likely that the greater SOC content was responsible. Several studies similarly reported that SOC contents were positively correlated with the degree of SWR (Mataix-Solera \& Doerr 2004) while others did not find such a relationship.

Figure 1 A: Macro-aggregate size distributions $(\mathrm{N}=6)$ in high- and low-soil organic carbon (SOC) pasture sites.

B: Mean contact angles for the four macroaggregate size fractions $(\mathrm{N}=3)$. The bars denote one standard deviation. The Figure is taken from Aslam et al. (2009).
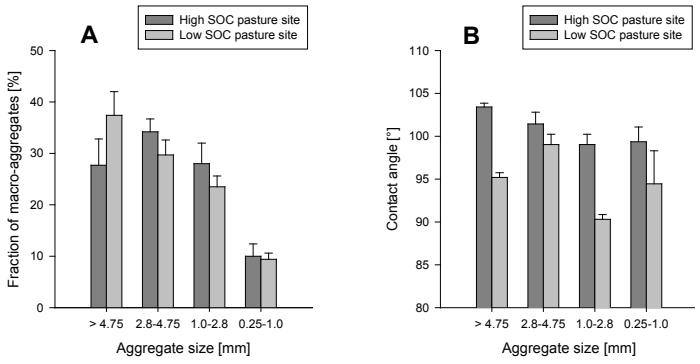

Aggregate size $[\mathrm{mm}]$ 


\section{Water infiltration in the field}

Dry soils at the end of summer should be buffers for precipitation because of high infiltration rates and low water storage. However, SWR reduced the soils' permeability by a factor of six and 20 in the low- and high-SOC soils, respectively (Fig. 2A). Reductions of the infiltration rate into water-repellent soils reported in the literature ranged from a factor of six (Wallis et al. 1990) up to 25 (DeBano 1971) compared with hydrophilic control soils.

\section{Soil water absorption by macro-aggregates}

Once water has infiltrated into the soil, the water absorption rate (= sorptivity) of the soil aggregates moves the water from the inter-aggregate macro-pores into the aggregates by capillary forces. Water inside the aggregates flows much slower than water in the interaggregate macro-pores and is stored, for example, for plant uptake. The ratios of the intrinsic sorptivities of

Figure 2 The ratio of the intrinsic permeabilities of ethanol to water $(\mathrm{A})$ and the ratio of the intrinsic sorptivities of ethanol to water of macro-aggregate size fractions (B) of two pastoral soils with different soil organic carbon (SOC) contents as a function of their respective contact angles.
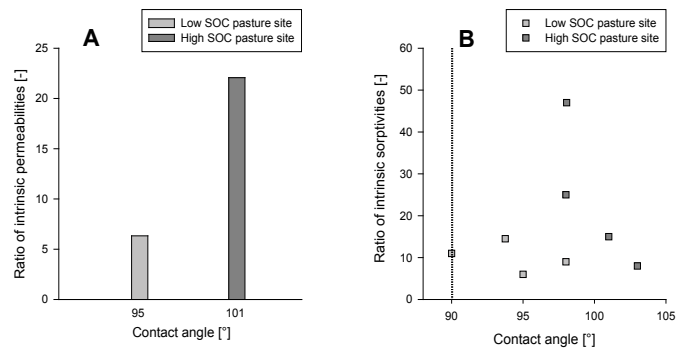

Figure 3 The filtering efficiency of 2,4-D at the high soil organic carbon (SOC) pasture site (extremely hydrophobic) and the low SOC pasture site (moderately hydrophobic). The bars denote one standard deviation.

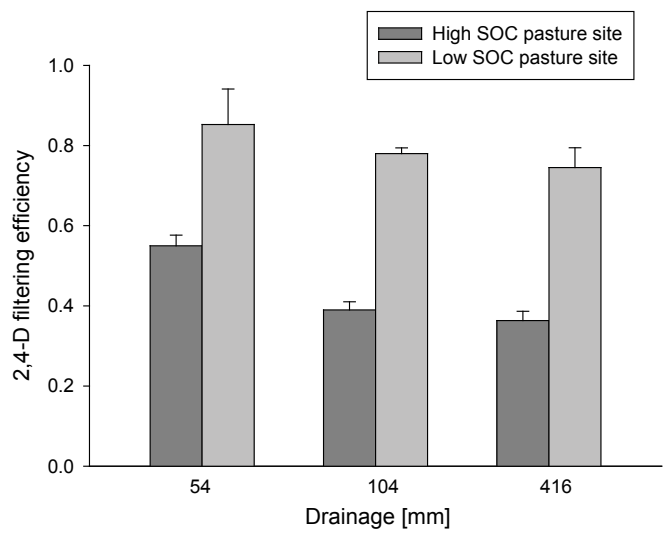

ethanol to water for the different macro-aggregate sizes of the two pastoral sites indicated a high reduction of water absorption due to SWR. The ratios ranged from about 5 to 50 (Fig. 2B). The ratio was, on average, higher by a factor of two in the high-SOC site than in the low-SOC site and increased in both systems with a decrease in the aggregate size. The CA could not predict the degree of reduction of the sorptivity (Fig. 2B).

\section{Filtering efficiency for the herbicide 2,4-D}

Aggregates also present a physical barrier to the downward transport of pesticides. Pesticides inside aggregates are either considered as immobile or travel much more slowly than in the inter-aggregate macropores. It is inside the aggregates where pesticide degradation and sorption processes predominantly take place. The reduced sorptivity of the high-SOC soil also prevented the uptake of the herbicide 2,4-D into the macro-aggregates, the soil's physical filtering process. This led to a poor overall filtering efficiency for 2,4-D in this extremely hydrophobic soil, in spite of its high SOC content. The less hydrophobic low-SOC soil had a significantly higher overall filtering efficiency (Fig. 3 ) than the high-SOC soil. Our results emphasise that the physical filtering of soils and its possible limitation by SWR should not be overlooked in the general estimation of a soil's filtering efficiency. We conclude that SWR can severely limit a soil's filtering efficiency for the herbicide 2,4-D.

\section{Pasture productivity}

Our results for water absorption indicate that water storage in the main root zone was limited by SWR. Our preliminary pasture production measurements show that SWR also affected pasture growth. Over 4 months, pasture production measured in the 'dry' patches was $50 \%$ less than that in the 'wet' areas surrounding them, and the 'dry' patches covered about $30 \%$ of the pasture. As expected, the areas in the 'dry' patches had

Figure 4 The degree of soil water repellency (contact angle) as a function of the soil organic carbon content of 15 pastoral sites with different soil orders across all regions of the North Island.

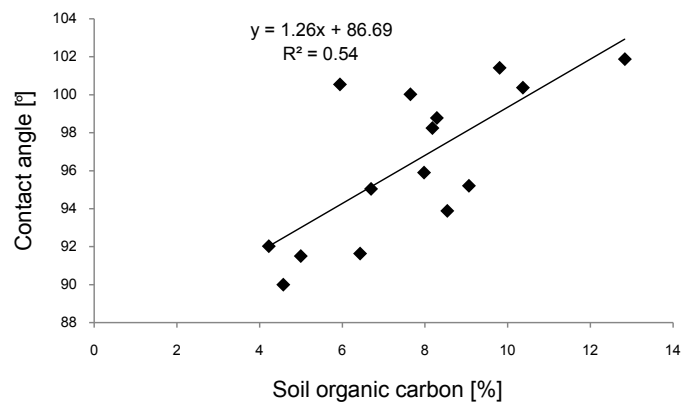


a higher degree and persistence of SWR, although these differences between the SWR of the 'dry' and the 'wet' patches were not as high as those determined during the drier summer of 2006 (Deurer et al. 2007). Our results support farmers' observations at Maraetotara that the increasing widespread occurrence of DPS leads to an estimated loss of $30-40 \%$ in pasture production (Slay 2008). As pasture production is strongly correlated with stock production, this represents losses of about $\$ N Z 180-360 /$ ha (Slay 2008). The gross margins are \$NZ600-1 200/ha (Slay 2008).

\section{Occurrence of SWR under pasture in the North Island} Initial results of our survey indicated that soils with SWR appear to be prevalent throughout all regions and independent of climate and soil order. About $25 \%$ of all topsoil samples were hydrophobic, with an actual WDPT larger than $5 \mathrm{~s}$. So far, 15 out of 50 sites have been completely analysed. The results for the subset of soil samples show SWR in $95 \%$ of the samples. SWR increased with increasing SOC content underlining its role for the occurrence of SWR (Fig. 4).

Our results show that SWR is a risk for pasture production in New Zealand, especially if climate change leads to a more regular occurrence of summer droughts. We need more research to close important knowledge gaps:

To understand better the source and evolution of SWR

To design efficient and affordable mitigation strategies.

\section{ACKNOWLEDGEMENTS}

We thank AGMARDT (Agricultural and Marketing Research and Development Trust) and SLURI (Sustainable Land Use Research Initiative) for funding our research on SWR.

\section{REFERENCES}

Aslam, T.; Deurer, M.; Müller, K.; Clothier, B.E.; Rahman, A.; Northcott, G.; Ghani, A. 2009. Does an increase in soil organic carbon improve the filtering capacity of aggregated soils for organic pesticides: A Case Study. Geoderma 152: 187-193.

Bisdom, E.B.A.; Dekker, L.W.; Schoute, J.F. 1993. Water repellency of sieved fractions from sandy soils and relationships with organic material and soil structure. Geoderma 56: 105-118.
DeBano, L.F. 1971. The effect of hydrophobic substances on water movement in soil during infiltration. Soil Science Society of America Journal 35: 340-343.

Dekker, L.W.; Ritsema, C.J. 1994. How water moves in a water repellent sandy soil 1. Potential and actual water repellency. Water Resources Research 30: 2507-2517.

Deurer, M.; Sivakumaran, S.; Müller, K.; Clothier, B. 2007. The 'Dry Patch Syndrome' in Hawke's Bay pastures - Is it caused by soil hydrophobicity? HortResearch Client Report No. 21678.

Driessen, P.M.; Deckers, J.; Spaargaren, O. 2001. Lecture notes on the major soils of the world. World Soil Resources Reports - 94. FAO, Rome.

Elliott, E. 1986. Hierarchic aggregate structure and organic $\mathrm{C}, \mathrm{N}$ and $\mathrm{P}$ in native and cultivated grassland soils. Soil Science Society of America Journal 50: 627-633.

Horne, D.J.; McIntosh, J.C. 2000. Hydrophobic compounds in sands in New Zealand-extraction, characterisation and proposed mechanisms for repellency expression. Journal of Hydrology 231232: 35-46.

Mataix-Solera, J.; Doerr, S.H. 2004. Hydrophobicity and aggregate stability in calcareous topsoils from fire-affected pine forests in southeastern Spain. Geoderma 118: 77-88.

Roy, J.L.; McGill, W.B. 2002. Assessing soil water repellency using the molarity of ethanol droplet (MED) test. Soil Science 167: 83-97.

Slay, M. 2008. Review: soil water repellency - its cause and possible amelioration strategies for hydrophobic soils at Maraetotara Hawke's Bay. Report M\&WNZ FITT project 07FT187 and AGMARDT project 21713.

Wallis, M.G.; Horne, D.J.; McAuliffe, K.W. 1990. A study of water repellency and its amelioration in a yellow brown sand: 1 . Severity of water repellency and the effects of wetting and abrasion. New Zealand Journal of Agricultural Research 33: 139-144.

Wallis, M.G.; Scotter, D.R.; Horne, D.J. 1991. An evaluation of the intrinsic sorptivity water repellency index on a range of New Zealand soils. Australian Journal of Soil Research 29: 353-362. 